\title{
HIGH VOLTAGE CIRCUIT BREAKER SUPPORTED ON A BASE ISOLATING TRIPOD FOR EARTHQUAKE PROTECTION
}

\author{
B. F. Safia, L. T. Pham, M. J. Busbyc
}

\begin{abstract}
The 1987 Bay of Plenty earthquake caused the total destruction of a $220 \mathrm{kV}$ circuit breaker. Failures occurred in the porcelain columns supporting the Interrupter Heads.

There are many other circuit breakers of the same type in the national grid. To protect these circuit breakers from earthquake damage, a proposal is made to replace the existing support stand with a base isolating tripod.

on the tripod, Helical springs and oil filled dampers are used to control the earthquake induced motion of the circuit breaker. By controlling this motion the forces on the porcelain support column are reduced to a safe level.

The design is modelled using a multi degree of freedom system subjected to Response Spectrum and Time History analyses. The model produces results which are consistent with tests, and confirms the design parameters selected by a single degree of freedom approximation.

The result is an economical tripod stand design which is expected to protect the circuit breaker from earthquake ground accelerations up to twice the level of the $1940 \mathrm{El}$ Centro earthquake. This level of earthquake is considerably stronger than the 1987 Bay of Plenty earthquake.
\end{abstract}

\section{INTRODUCTION}

The 1987 Bay of Plenty earthquake was of magnitude (ML) 6.3, and the epicentre was located about $8 \mathrm{~km}( \pm 5 \mathrm{~km})$ from Edgecumbe substation, where the oerlikon FS9C1 circuit breaker (CB) was destroyed [7]. The peak ground acceleration measured at the base of the Matahina Dam was $0.33 \mathrm{~g}$.

The earthquake was strong enough to cause severe damage to houses, and extensive minor damage to roads. other electrical equipment including Merlin Gerin $220 \mathrm{kV}$ CB, and numerous current transfomers and Power Transformers at Edgecumbe and Kawerau Substations were damaged or destroyed [9].

The Oerlikon FS9cl circuit breaker was severely damaged during the 1987 Bay of plenty Earthquake. The lower and middle porcelain insulators broke due to high acceleration forces acting on the $692 \mathrm{Kg}$ "Y" shaped interrupter heads. See Figures 1 and 2 .

\footnotetext{
Engineer

Consultant

Design Engineer

DesignPower NZ Ltd, Wellington
}

Before the earthquake struck, it was known that this breaker would not survive an earthquake of this magnitude. Oerlikon FS9Cl CB's were purchased prior to the Electricity Corporation of $\mathrm{NZ}$ Ltd adopting its current earthquake resisting standards, and were only required to have a breaking strength of better than $0.25 \mathrm{~g}$.

These and a number of other circuit breakers were on a list of equipment to be checked and strengthened, but this work had not been done at the time of the Bay of Plenty Earthquake.

Oerlikon FS9cl $220 \mathrm{kV}$ Circuit Breakers are currently used by the Electricity corporation of NZ Ltd at a number of substations, and play an important role in the power transmission network. Each $3 \mathrm{x}$ single phase breaker is rated at 10,000 MVA (maximum), or 2000 amperes continuous current.

The circuit breakers have a replacement cost of about $\$ 120,000$ per three phase unit.

At Trans Power NZ Ltd's request DesignPower undertook to design an economical method of ensuring the survival and continued operation of the Oerlikon circuit breakers during and after design earthquake conditions. 


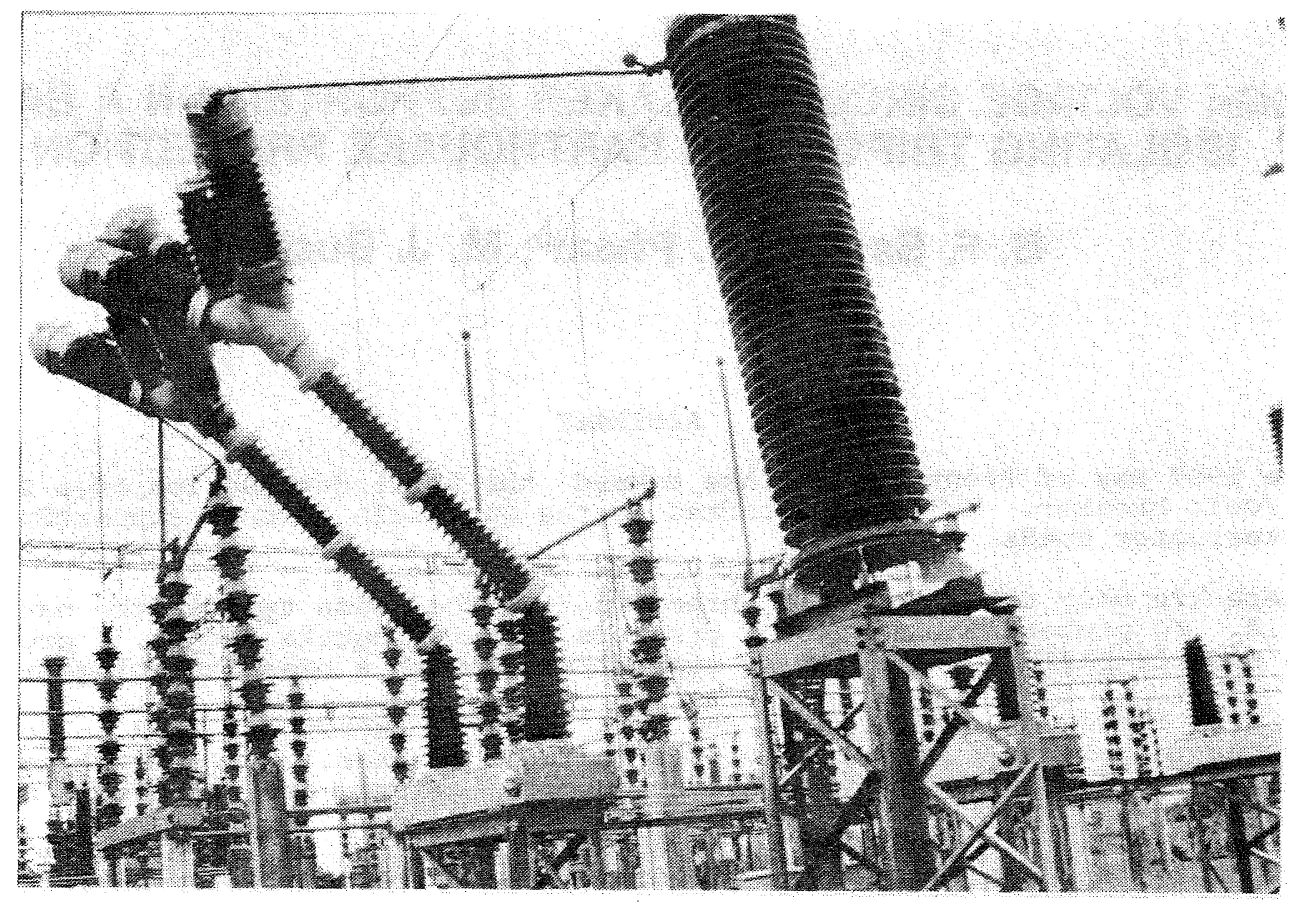

PHOTO 1: The damaged FS9c1 circuit breaker at Edgecumbe. Note the position of the porcelain failure, at the top of the lower support insulator.

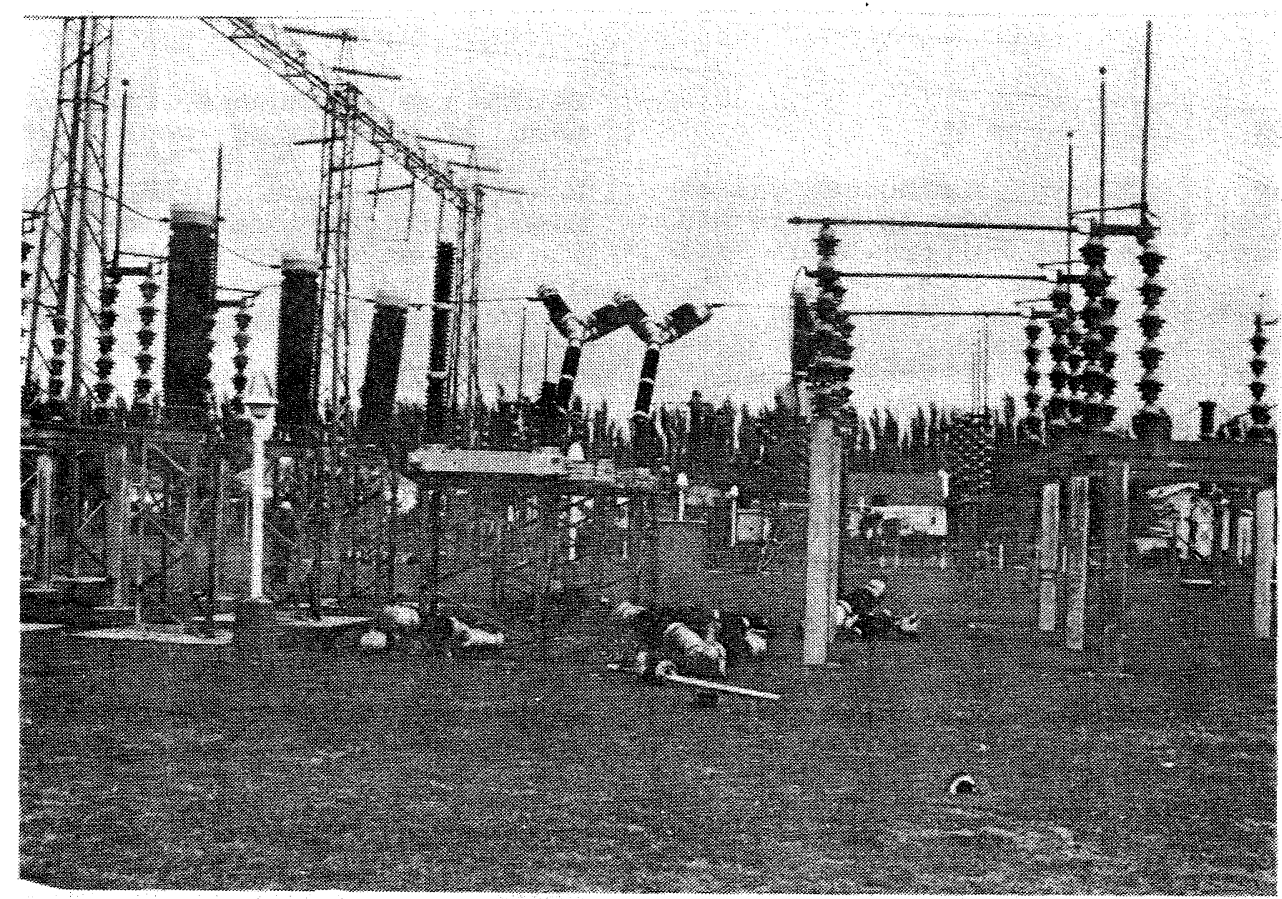

PHOTO 2: Another view of the same breaker. The other two phases are totally destroyed, and the broken pieces are on the ground. 
This paper introduces the topic of base isolation as it applies to high voltage electrical switchgear. The selection of basic design parameters by approximation as a single degree of freedom vibrating system is explained and the design of the tripod stand is described.

The circuit breaker is modelled as a multidegree of freedom system, both on the original stand and on the tripod stand. The stress results of Response spectra and Time History analysis for the original and new arrangement are compared.

Stress and displacement results from the model and the central Laboratories Tests $[1,2]$ are also compared, to check the validity of the model.

\section{BASE ISOLATION APPROACH}

It would be possible to increase the strength of the circuit breaker by providing stronger, larger diameter porcelain support members. This approach was considered, but rejected as being expensive, both in terms of the high grade porcelain required for strengthening, and in terms of downtime to rebuild the circuit breakers.

For these reasons, base isolation of the $C B$ was chosen as the best solution. This method is becoming widely used on structures and equipment of various sizes, and has been used for Electricorp Circuit Breakers in the past $[5,11,8]$.

The principle of base isolation is fairly straightforward. The equipment concerned is mounted flexibly so that the natural frequency of oscillation of the system is moved out of the critical 1 to 10 Hertz frequency range. For typical New Zealand substation ground conditions, it is in this range the largest amplifications of earthquake induced ground accelerations occur.

Problems that can occur with base isolation are:

1. The displacements at the lower natural frequency can be large.

2. This amount of flexibility can be difficult to achieve in practice.

There are various methods of achieving base isolation. One method suitable for heavy objects is lead-rubber bearings as used on the Works Corporation William Clayton building [9]. This method was not suitable here because of the comparatively light weight $(2,160 \mathrm{~kg})$ of the circuit breaker. commercially available lead-rubber bearings are sized for use with structures of much heavier weight.

Another method would be to mount the circuit breaker on spherically ended rollers [8]. This method was not suitable because the high centre of gravity of the $\mathrm{CB}$ structure would cause strong overturning moments, which the rollers are not designed to cope with.
A rotational system controlled with helical springs and viscous oil dampers was chosen instead. Helical springs are cheap to make, and can easily be manufactured to the force and displacement requirements. Their rate can be accurately calculated, and so a close tolerance on the natural frequency of the design can be achieved.

Viscous oil filled dampers are used. These are available as standard manufactured units, and their damping rate is accurately determined. They are only moderately expensive (about $\$ N Z$ 550). They have a life of millions of cycles, far in excess of what is required for earthquake protection, and they are not adversely affected by many years of inactivity.

An oil filled dampers which had been installed in an outdoor substation for fifteen years was tested and found to operate very closely to the original design specification. Corrosion or oil leakage had not been a problem [4].

\section{DESIGN DATA}

To confidently design a new arrangement, some properties of the circuit breaker would need to be determined:

1. The natural period and damping of the porcelain column and head.

2. The breaking strength of the porcelain in bending. Because the strength of porcelain depends on the loading, testing to destruction is the best method of determining this.

Tests were carried out by Works Central Laboratories in May and July of 1988 to determine these properties $[1,2]$ (see Table 1).

Accurate data for the weight and dimensions of the circuit breaker parts are also required. This data was obtained from measurement of spare circuit breaker parts at Bunnythorpe Substation.

The Design Criteria used was Trans Power's Response Spectra for their Design Earthquake (see Figure 4).

\section{FREQUENCY OF THE NEW SYSTEM}

The Trans Power standard response spectra (Figure 4) shows the effect of natural period on the acceleration response of the structure. Increasing the period from one second to two seconds gives a substantial decrease in the acceleration. Increasing beyond two seconds decreases the acceleration further, but only by a small amount.

For these reasons, two seconds was initially selected as the design natural period of the system. This reduces the acceleration response from $1.3 \mathrm{~g}$ (acting at the centre of gravity) for the original arrangement, to $0.15 \mathrm{~g}$ for the new stand.

The spring and damper rates were determined by equating the circuit breaker and springs 


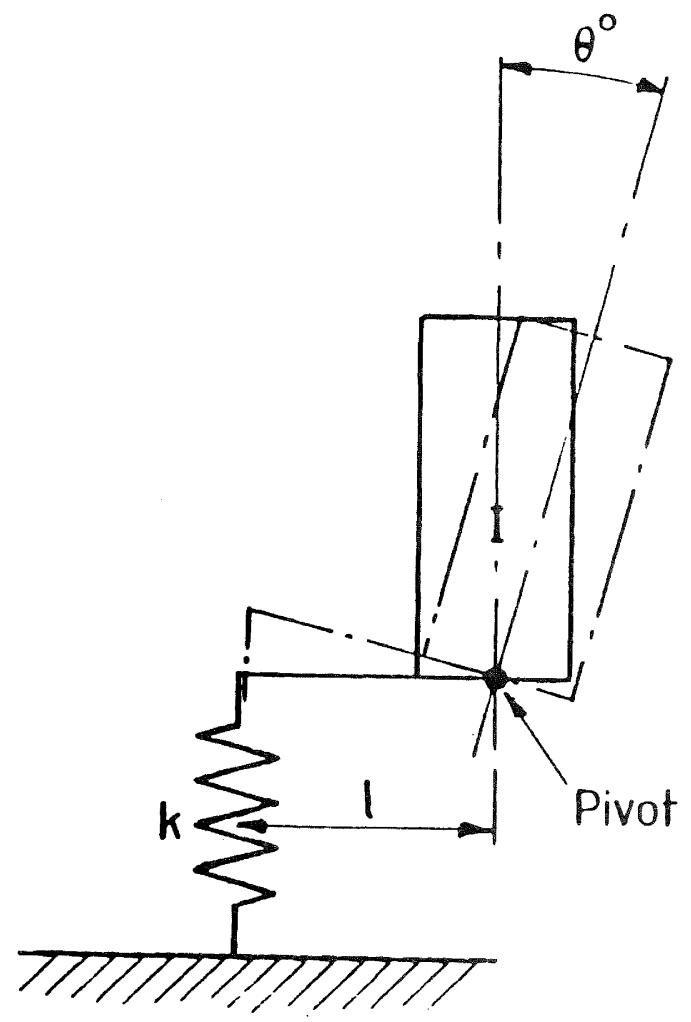

FIGURE 3. SINGLE D.O.F. MODEL.

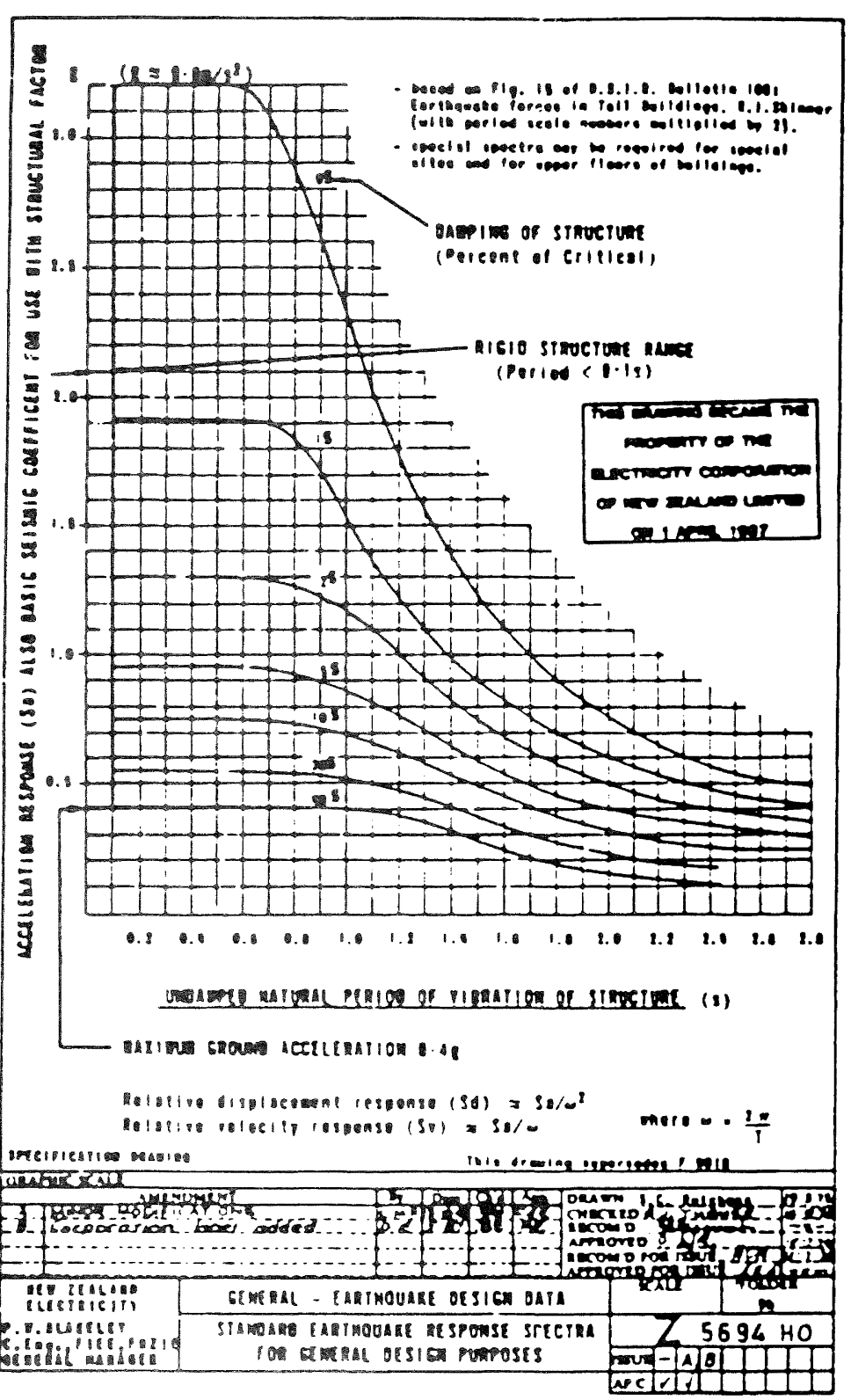




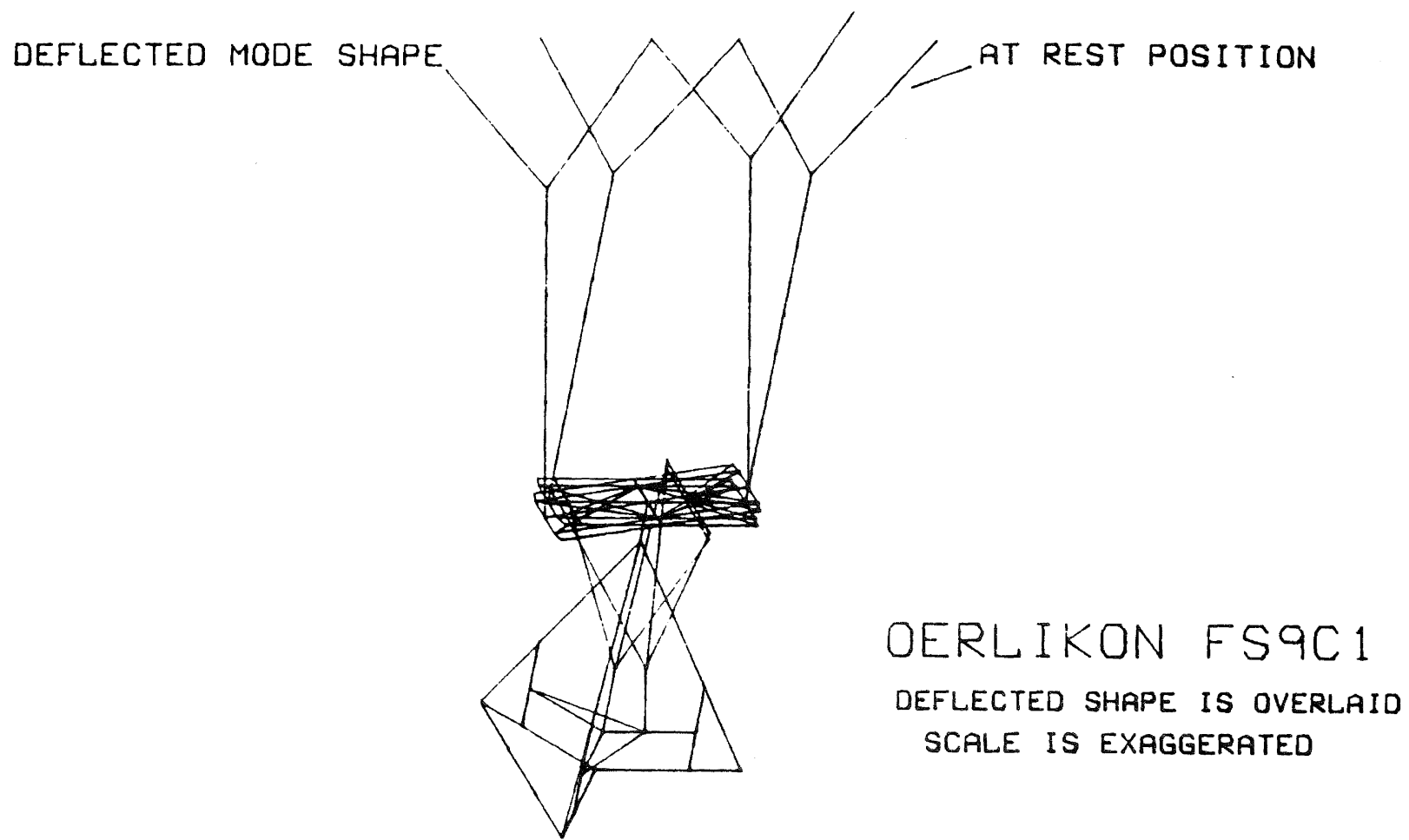

FIGURE 5. DEFLECTED MODE SHAPE.

to a single degree of freedom system (SDOF) as shown in Figure 3 .

Since the spring stiffness is significantly softer than any other part of the system, this SDOF approximation is reasonably accurate.

The natural period was reduced to 1.8 seconds after analysis of wind forces showed that the 2.0 second period springs were too soft to prevent the circuit breaker from significant sway in the wind. Wind conditions for Bunnythorpe Substation were obtained from NZS 4203:1984.

At 1.8 seconds the acceleration response is $0.18 \mathrm{~g}$, still well below the failure level of the porcelain, which is estimated at $0.56 \mathrm{~g}$.

These results were refined later when the frequency of the system as a multi-degree of freedom system is estimated.

\section{DESCRIPTION OF THE TRIPOD}

The tripod stand is tetrahedral in shape with three RHS legs and a channel steel base. An "arm" comes down from the circuit breaker support frame as three tubes in an inverted tetrahedron, joining into one vertical tube (see Figure 6).

The fabrication procedure for the stand has been considered, and location buttons and other features have been provided to keep the staind straight, symmetrical, and easy to assemble.
At the top of the stand is a universal joint which allows the $C B$ to rock in any direction, but not to rotate about its vertical axis.

As the $C B$ rocks, its motion is resisted by three springs and three viscous dampers attached to the vertical arm tube.

The other end of the springs and dampers are mounted on $50 \mathrm{~mm}$ rods so that their position can be altered. This allows about b10\% adjustment of the natural period.

Note that the $\mathrm{CB}$ is on a $2.1 \mathrm{~m}$ high stand for reasons of electrical safety.

The cost of fabrication and erection of tripod stands for one three phase circuit breaker is estimated at $\$ 24,500$.

\section{OTHER MODIFICATIONS REQUIRED}

The circuit breaker uses high pressure ( 340 bar) oil to operate. This oil is supplied by one pump for all three phases. The pump is located in a control cabinet near to the middle breaker, and oil is piped to and from each $C B$ by three $16 \mathrm{~mm}$ pipes. To allow for movement of the $C B$ (estimated at $\pm 50 \mathrm{~mm}$ at the pipe location), a section of flexible hydraulic hose was required. This was arranged in a "U" shape for compactness.

The control box was previously mounted as part of the original stand. It could not easily be mounted on the tripod stand, and so a small separate stand was provided. 


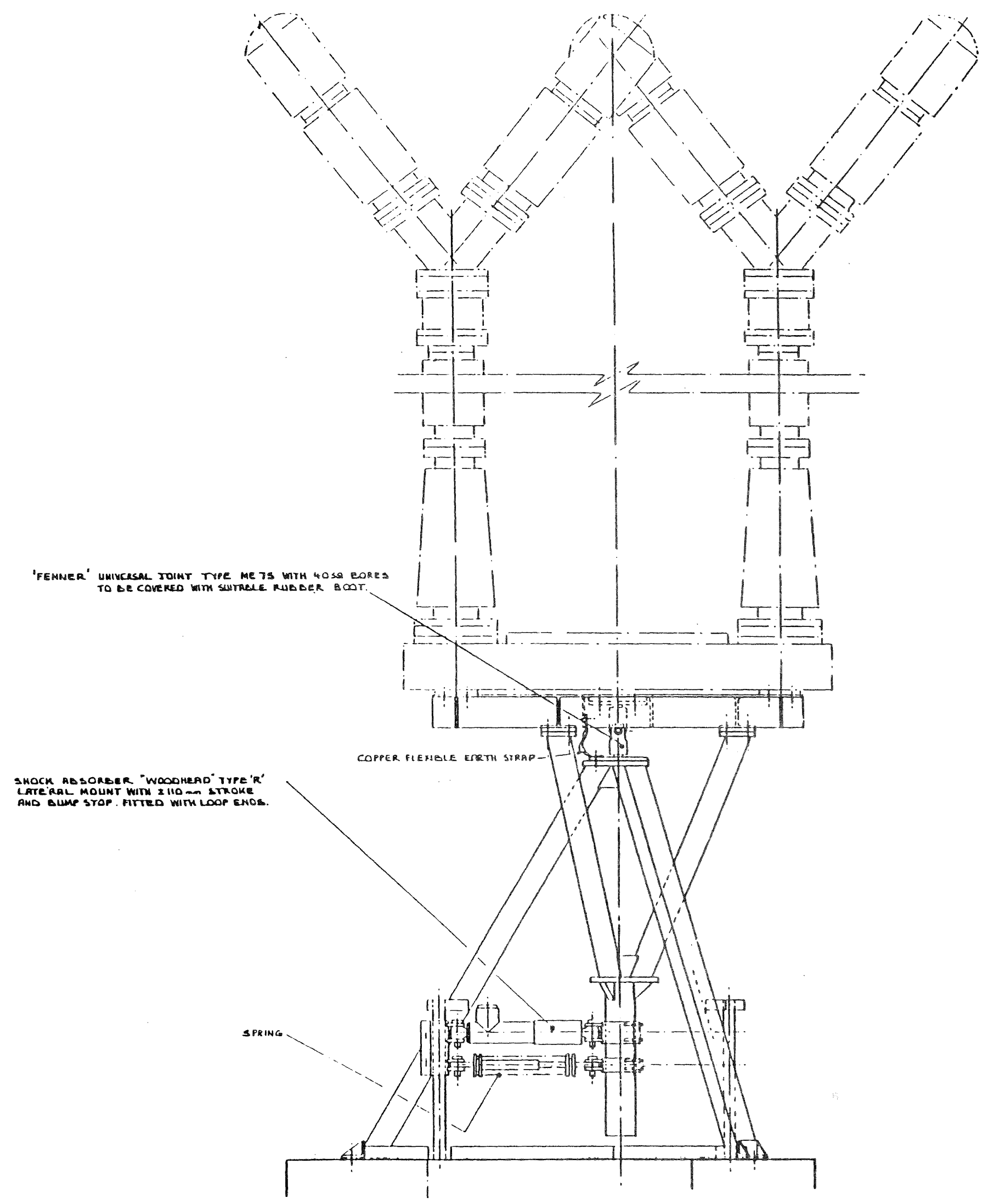

FIGURE 6. GENERAL ARRANGEMENT OF ONE PHASE OF THE OERLIKON CIRCUIT BREAKER ON THE TRIPOD STAND. 
The foundations of some $C B^{\prime}$ 's were not large enough to mount the tripod stands. Small sections of reinforced concrete were added to these foundations to provide sufficient room for mounting, and also to give enough foundation weight to prevent overturning of the pad under seismic loads.

The displacement at the top of the $C B$ is calculated at a maximum of $\pm 180 \mathrm{~mm}$. It is now standard Trans Power practice to allow for $\pm 300 \mathrm{~mm}$ for high voltage electrical connections. This movement is allowed for by arching the flexible conductor which connects the $C B$ to nearby equipment.

\section{MODELLING OF THE EXISTING STAND AND CIRCUIT} BREAKER

This was done for two reasons.

1. To verify that the circuit Breaker model on the existing stand would predict a failure mode similar to that which occurred at Edgecumbe

2. To ensure that the $C B$ model was sufficiently accurate by comparing stress, displacement, and natural period for the model and the central Laboratories tests made on the real circuit breaker.

"Beam" elements were used for the entire model (except the springs). These are three-node finite elements for which area and material properties must be specified.

These elements were well suited for the porcelain parts and for the steelwork in the stand.

Density was increased in the porcelain elements to take account of the metal parts, oil, and other fittings that made up the weight of the real circuit breaker.

MODELLING OF THE NEW TRIPOD STAND AND CIRCUIT BREAKER

The tripod stand and arm assembly had been modelled with beam elements for structural design purposes.

To model the new system, these parts were merged with the original model of the circuit breaker (less its stand), and springs (in the form of boundary elements) were added.

Boundary elements make ideal springs, since their length and spring rate can be easily defined.

The universal joint was made by releasing two rotational degrees of freedom at the end of the appropriate beam.

\section{RESPONSE SPECTRUM ANALYSIS}

Standard Trans Power response spectra for $2 \%$ and $40 \%$ of critical damping (Figure 4) were used.

\section{TIME HISTORY ANALYSIS}

Ground acceleration records for 7.8 seconds of the $1940 \mathrm{El}$ Centro earthquake were used. These were scaled up by factors of 1.4 (Equivalent to the Trans Power standard design earthquake) and 2.0 (about the maximum level allowable for this design).

The 7.8 seconds was divided into 1560 time steps of 0.005 seconds for analysis.

\section{RESULTS OF ANALYSIS}

The model of the circuit breaker without its stand gave a natural frequency of 3.56 Hertz. This is slightly higher than the works central Laboratories test result of 2.6 Hertz. The higher natural frequency of the model may be caused by the fact that gaskets, bolt flexibility, and other details are not taken into account. The results are close enough to allow a reasonably accurate analysis of the stresses resulting.

A summary of the force, deflection and stress results for the model and the test data is shown on Tables 1 and 2 .

The frequency of the circuit breaker on its original stand was 2.7 Hertz. When analysed with the Electricorp response spectrum for $2 \%$ damping, a stress of $46 \mathrm{MPa}$ resulted. This high stress occurred in the bottom of the middle insulator column, which is made of thinner porcelain than the lower column. This is near to where the real circuit breaker broke in the Bay of plenty earthquake.

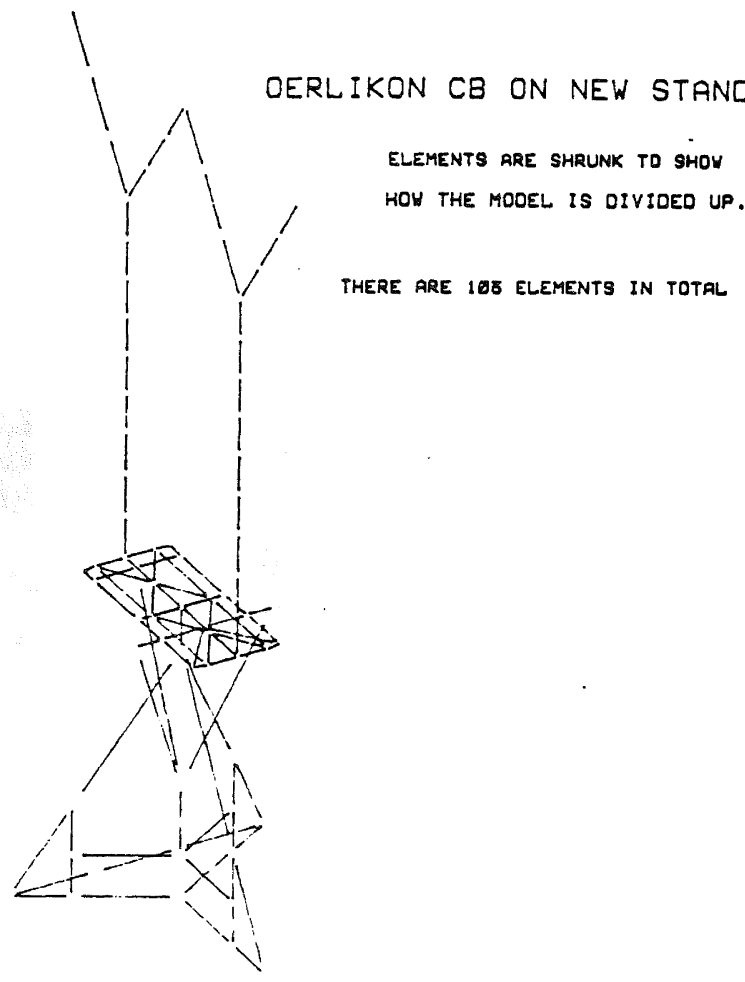

FIGURE 7. OERLIKON CIRCUIT BREAKER ON NEW STAND. 
TABLE 1. CENTRAL LABORATORIES TEST RESULTS COMPARED WITH THE FINITE ELEMENT MODEL

\begin{tabular}{|l|c|c|c|}
\hline & $\begin{array}{l}\text { Deflection at } \\
\text { Point of } \\
\text { Application of } \\
1800 \mathrm{~N} \text { Force }\end{array}$ & $\begin{array}{c}\text { Stress in the } \\
\text { Support Column } \\
\text { with a 10.68 kN } \\
\text { Cantilever Load }\end{array}$ & $\begin{array}{c}\text { Natural } \\
\text { Frequency } \\
\text { of Column }\end{array}$ \\
\hline $\begin{array}{l}\text { Test } \\
\text { Result }\end{array}$ & $6.8 \mathrm{~mm}$ & $22.8 \mathrm{MPa}$ & $2.6 \mathrm{~Hz}$ \\
\hline $\begin{array}{l}\text { Model } \\
\text { Result }\end{array}$ & $7.1 \mathrm{~mm}$ & $22.5 \mathrm{MPa}$ & $3.5 \mathrm{~Hz}$ \\
\hline
\end{tabular}

TABLE 2. HIGHEST STRESSED PORCELAIN ELEMENT IN THE CIRCUIT BREAKER (stress in $\mathrm{MPa}$ )

MODE 2 IS THE CB ON THE ORIGINAL STAND - 2\% DAMPING MODE 40 IS THE CS ON THE TRIPOD STAND - $40 \%$ DAMPING

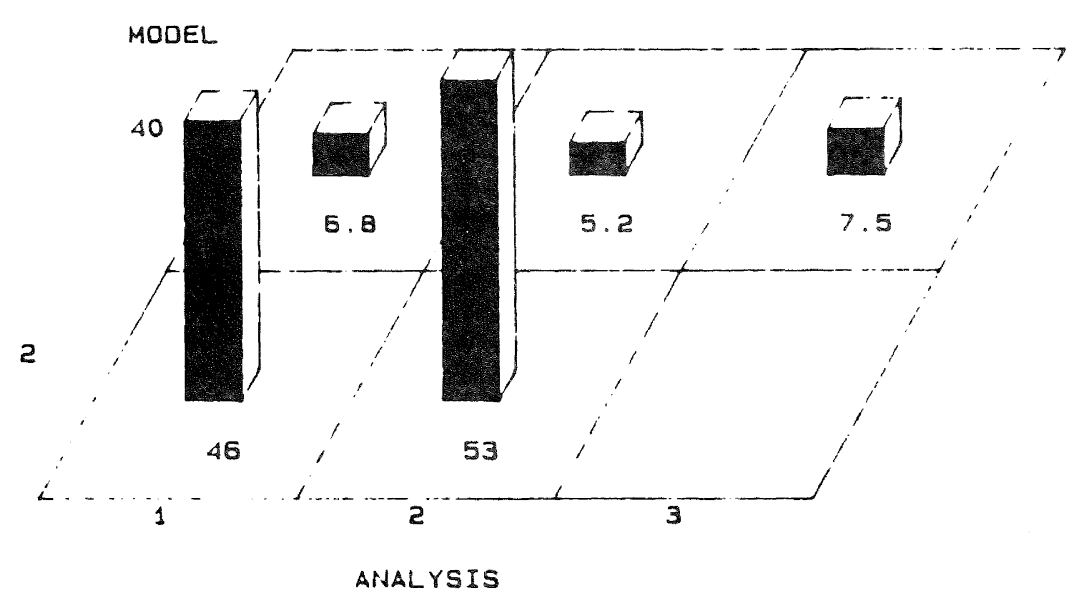

ANALYSIS 1 IS THE TRNSPOWER RESPONSE SPECTRUM ANALYSIS 218 1.4X ELCENTRO TIME HISTOPY ANALSI8 3 IS 2.OX ELENTRO TME HSTORY 


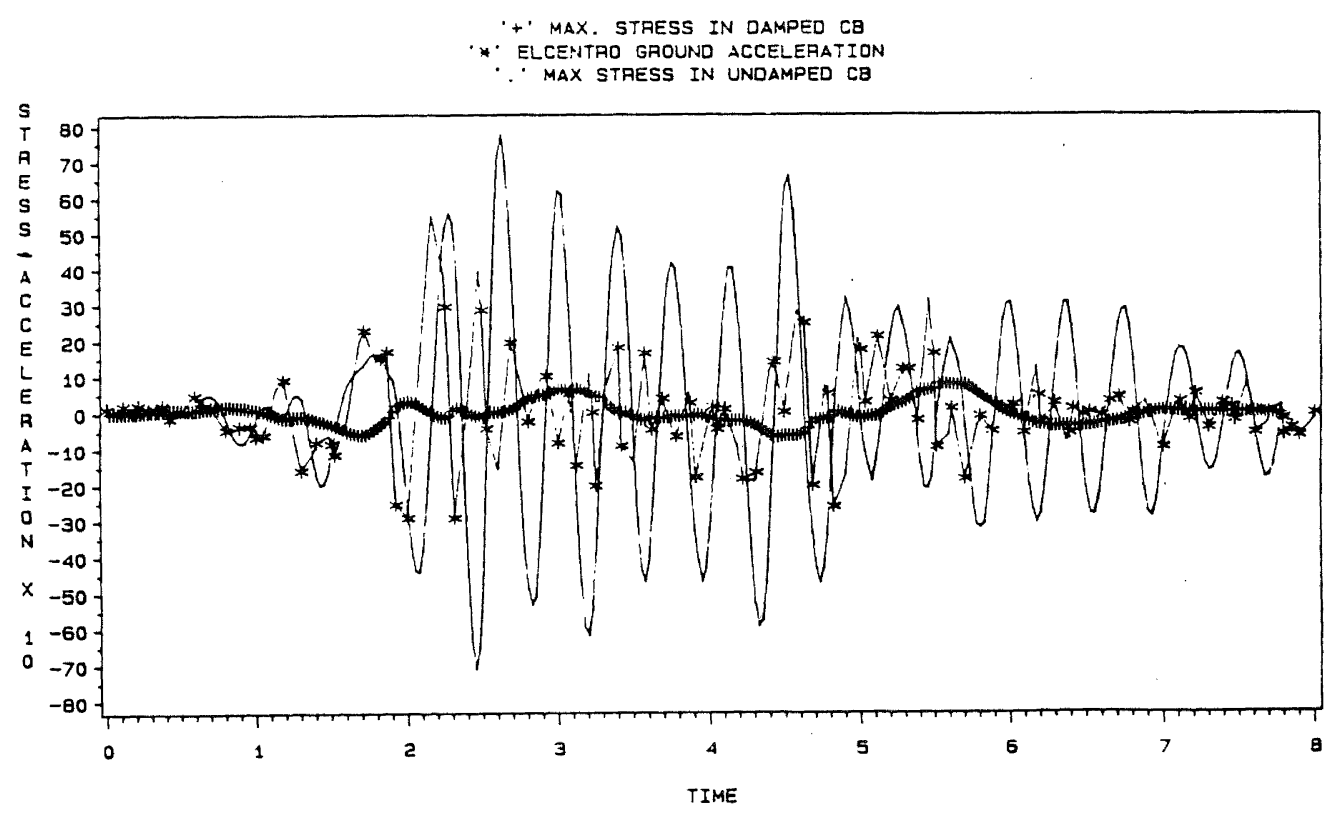

GROUND ACCELERATION IN M/SEC'2 SCALED X10 FOR CLARITY STRESS IN MPA; TIME IN SECONDS

FIGURE 8. OERLIKON CIRCUIT BREAKER TIME HISTORY ANALYSIS.

The circuit breaker on its original stand was also analysed with ground acceleration records from the 1940 El Centro Imperial valley earthquake, scaled up by a factor of 1.4. The reason for the scale factor is to give a magnitude approximately equal to the Trans Power design earthquake.

This Time History analysis resulted in a maximum stress of $53 \mathrm{MPa}$ in the same porcelain member as for the Response spectrum analysis.

From these results we can deduce failure of the $\mathrm{CB}$ on its original stand at a magnitude of:

$$
1.4 \times \frac{22.8}{53}=0.6
$$

ie. 0.6 times the El Centro earthquake

According to Dowrick [3], Edgecumbe ground accelerations were somewhat weaker than those for El Centro, perhaps about $80 \%$ of El Centro. At this level, destruction of the circuit breaker on its original stand can be expected.

The acceleration response required to damage the $C B$ can also be estimated. This would be equal to the ratio of the breaking stress of the porcelain over the stress in the model ( $53 \mathrm{MPa}$ ) times the acceleration response at $2 \%$ damping 53

$$
=\underline{22.8} \times 1.3 \mathrm{~g}=0.56 \mathrm{~g} \text { (approximately) }
$$

\section{ANALYSIS OF THE NEW STAND}

The new stand was analysed with the Electricorp Response Spectrum for $40 \%$ damping and Time History data for El Centro scaled up by 1.4 , and 2.0 .

The resulting stresses are summarised in Table 2. The porcelain stress has been reduced to about $1 / 3$ of the breaking stress.

For the time history analysis at 2.0 times El Centro, the displacement of the CB just reaches the travel limit of the dampers. This is the expected failure mode. the dampers reach their travel limit at a ground acceleration of $0.8 \mathrm{~g}$ approximately. This corresponds to an earthquake intensity with a return period of about 1000 years [6].

This level should be more than adequate for protection of the Circuit Breaker.

\section{CONCLUSIONS}

An Oerlikon FS9cl circuit breaker mounted on the tripod stand is expected to survive an earthquake of about twice the magnitude of El Centro (1940) or two and a half times the magnitude of the 1987 Edgecumbe earthquake.

The design is cost-effective and makes use of reliable, readily available components.

Modifications of the circuit breaker itself are minimal, and hence the down time required for fitting the new stand is low. 
The new design has yet to be tested, but the analysis gives results consistent with tests done on circuit breaker components, and for this reason it is expected that the tripod will perform as designed.

\section{REFERENCES}

1. Central Laboratories report 88-B5407 "Bending Tests on Oerlikon Insulator", May 1988, D.H. Jacks.

2. Central Laboratories Report 88-B5407/1, "Stiffness and Damping Tests on Oerlikon Insulator Tower", July 1988, R.B. Stevenson.

3. DOWRICK, D J, (1989), "A Comparison of Three Shallow Earthquakes - Edgecumbe 1987, Kalamata 1986, and Imperial Valley 1940", IPENZ Proceedings Annual Conference 1989, Vol 1.

4. DSIR, Report No. 512091, "Report on Performance Tests on Telescopic Dampers", March 1985.

5. GILMOUR, $R$ M, and Hitchcock, $H$ C (1971), "Use of Yield Ratio Response Spectra to Design Yielding Members for Improving Earthquake Resistance of Brittle Structure", Bulln, NZ National Soc. for Earthquake Eng. Vol 4, No.2, April 1971.
6. MATUSCHKA, T, et al (1985), "NZ Seismic Hazard Analysis", Bulln NZ National Soc. for Earthquake Eng. Vol 18, No. 4, December 1985.

7. PENDER, $M J$ et al (1987), "Edgecumbe Earthquake : Reconnaissance Report" Bulln NZ National Soc. for Earthquake Eng Vol 20, No.3, September 1987.

8. PHAM, L T (1988), "A Base Isolation Design Using Spherically Ended Rollers and Telescopic Shock Absorbers", Bulln $\mathrm{NZ}$ National Soc. for Earthquake Eng Vol 21 , No.2, June 1988.

9. RUTLEDGE, A L (1988), "Earthquake Damage at Edgecumbe and Kawerau Electricorp substations in the Bay of Plenty Earthquake on 2 March 1987", Bulln NZ National Soc. for Earthquake Eng Vol 21, No.4, December 1988.

10. SKINNER, $R$ I, Tyler, $T$, Heine, A J and Robinson, $W$ H, (1980), "Hysteretic Dampers for the protection of Structures from Earthquakes", Bulin NZ National Soc. for Earthquake Eng Vol 13, No.1, March 1980.

11. WINTHROP, D $A$, and Hitchcock, $\mathrm{H} C$ (1971), "Earthquake Design of Structures with Brittle Members and Heavy Artificial Damping by the Method of Direct Integration", Bulln, NZ National Soc, for Earthquake Eng Vol 4, No.2, April 1971. 